\title{
¡A LUJÁN! \\ LAS COMUNIDADES DE INMIGRANTES Y EL NACIENTE CATOLICISMO DE MASAS, 1910-1934
}

\author{
POR \\ MIRANDA LIDA* \\ Universidad Católica Argentina y Universidad Torcuato Di Tella. \\ Investigadora en el CONICET. Argentina
}

El objetivo de este trabajo es explicar el fenómeno de las movilizaciones de las comunidades de inmigrantes a Luján a partir de una consideración del cuadro general en el que se inscribian. Este cuadro ha de incluir el contexto general del catolicismo argentino hacia el Centenario, a fin de llamar la atención sobre el hecho de que los italianos no fueron los únicos ni los primeros que se movilizaron a Luján en procesiones cada vez más multitudinarias. Nos interesa focalizar, pues, la década de 1910, años en los cuales las procesiones y manifestaciones católicas se vuelven cada vez más numerosas. Usualmente, la historiografía suele ubicar la aparición del catolicismo de masas en la década de 1930, cuya expresión más elocuente se habría encontrado en la celebración del Congreso Eucarístico Internacional de 1934. Sin embargo, suele olvidarse que el primer evento de estas características se celebró en Buenos Aires en fecha tan temprana como 1916, cuando se celebró el primer Congreso Eucarístico Nacional. Éste se hizo eco de la naciente oleada de movilización católica de masas que vio la luz hacia el Centenario. De ella fueron partícipes, entre otros, los italianos.

PALABRAS CLAVE: Inmigración, catolicismo, politica de masas, movimientos sociales, Buenos Aires.

* Profesora en la Universidad Católica Argentina y en la Universidad Torcuato Di Tella. Investigadora en el CONICET. Argentina. Agradezco los comentarios de los evaluadores anónimos de Revista de Indias. 


\section{INTRODUCCIÓN}

La relación entre los inmigrantes llegados masivamente a la Argentina desde fines del siglo XIX y el fenómeno religioso dio lugar a un gran acervo de estudios; distintas líneas de investigación se han desarrollado en torno a este tema. Comenzaremos por hacer un breve repaso de las más importantes para luego presentar nuestra propia investigación.

Quizás una de las áreas más exploradas tiene que ver con el impacto de la inmigración sobre las estructuras eclesiásticas y la conformación del clero' ${ }^{1}$. Aquí se cuentan desde estudios de caso guiados por criterios cualitativos hasta análisis de vocación más general. Existe un fuerte consenso en torno a que la inmigración proporcionó importante número de personal eclesiástico, tanto en el clero secular como en el regular, aunque quizás se hiciera notar mucho más entre este último ${ }^{2}$. De impacto desparejo en todo el territorio del país, al igual que lo que ocurre con el fenómeno inmigratorio en general, su presencia no puede ser desdeñada. A pesar de que la Constitución de 1853 exigía el acuerdo del Congreso para el ingreso de las congregaciones extranjeras, éstas llegaron en gran número y sin mayores trabas ${ }^{3}$. Los aportes inmigratorios a las instituciones eclesiásticas son innegables, más allá de los matices que puedan presentarse según nacionalidad de origen y diócesis de destino.

Asimismo, también se ha considerado la faceta inversa de esta relación: qué aportes hizo la institución eclesiástica desde sus diversas instituciones para la evangelización de los inmigrantes y si acaso la Iglesia tuvo una política (del tipo que fuere) para con los recién llegados. Aquí el consenso es menos nítido, puesto que los historiadores oscilan desde algunas tesis optimistas hasta otras que lo son menos ${ }^{4}$. (Este debate entre los optimistas y los pesimistas se vincula con la discusión en torno a la movilidad social del inmigrante, desde aquellos que afirman sin matices que la Argentina fue una

1 Asimismo, tampoco se ha descuidado el análisis de su impacto sobre la religiosidad, las nuevas devociones que los inmigrantes trajeron consigo y las nuevas formas de expresar la piedad religiosa, en sus diferentes aspectos, desde el ritual hasta la arquitectura o el arte sacro. En este sentido, Martín Castro, 1996: 569-591; María Liliana da Orden, 1991: 379-402; Susana Beatriz Martos, 2005: 53-76, entre otros trabajos. Esta línea fue sin embargo la que con mayor peso se desarrolló en Estados Unidos, otro país de inmigración. Véase por ejemplo Robert Orsi, 1985.

2 Entre otros trabajos, Néstor T. Auza, 2001: 279-295; Nora Siegrist de Gentile, 1991: 153-176; Edgardo Stoffel, 1997: 71-99; Edgar Stoffel, 1994: 61-85; Néstor Auza, 1994, 43-59.

3 Fue decisivo, en este sentido, un dictamen de Dalmacio Vélez Sársfield de 1857 que se halla reproducido en Santiago Ussher, 1955: 128-132.

4 Néstor Auza, 1990: 105-137; Mariela Ceva, 2000; Daniel J. Santamaría, 1990: 139-180. 
tierra de oportunidades, hasta aquellos otros que muestran que el inmigrante sólo con gran dificultad pudo ver realizado el sueño del ascenso social). Un aspecto que se deriva de aquí es la focalización en torno a la cuestión social y las prácticas e iniciativas católicas a favor del bienestar obrero. Las posiciones varían entre aquellas que sugieren una amplia preocupación eclesiástica por la materia, hasta otros autores en los que ésta aparece más bien relativizada $^{5}$.

Una tercera línea de investigación tiene que ver con la relación entre inmigrantes, la política y la cuestión religiosa. La primera cuestión - la relación con la política - ha sido revisada, en especial, a partir del trabajo de Ezequiel Gallo sobre las colonias de inmigrantes de Santa Fe, quien mostró que los inmigrantes encontraban diferentes vías para la participación política, a pesar de su exclusión formal del voto en las elecciones nacionales ${ }^{6}$. Que su presencia en la esfera pública no se hallara constreñida por las limitaciones impuestas por la ley electoral a nivel nacional se hace evidente a través de su participación en diferentes polémicas que involucraron a la religión católica y su presencia en el espacio público, como en el caso de los italianos de La Boca que estudió Fernando Devoto ${ }^{7}$.

No ha sido explorada, sin embargo, la movilización de los inmigrantes en torno a la religión en periodos posteriores al fin de siècle y en buena medida a revisar esta cuestión se dedica este trabajo. Ello fue así, quizás, porque se dio por descontado que la movilización y la agitación católicas, que se hicieron sentir en ocasión de las polémicas de la década del 80, no habrán de reaparecer en escena sino en la década de 1930, estrechamente vinculada al renacimiento católico de esos años ${ }^{8}$. Si bien en la historiografía no se pasó por alto el hecho de que los italianos han logrado orquestar importantes movilizaciones y procesiones que tenían por destino el santuario de Nuestra Señora de Luján, se ha tendido a explicar este fenómeno más por el dinamismo de los italianos — sin duda la mayor colectividad extranjera en la Argentina - que por cualquier otra lógica extrínseca a la propia comunidad inmigratoria. Se ha tendido a considerar más que nada una excepción, en una época en que el catolicismo parecía encontrarse más bien «aletargado», sin una vasta presencia en la esfera públi$\mathrm{ca}^{9}$. Asociar linealmente la inmigración, en tanto que factor de modernización de la sociedad argentina, a la secularización, el laicismo o incluso el anticleri-

5 Mariela Ceva, 2005: 585-602; Gianfausto Rosoli, 2000: 211-239.

6 Ezequiel Gallo, 2004. Este tema fue retomado por Eduardo Míguez, 1987: 337-378.

7 Fernando Devoto, 1991: 199-229.

8 Loris Zanatta, 1996.

9 En este sentido, Miranda Lida, 2005. 
calismo, es - como ya ha sido sugerido por Tulio Halperin Donghi - un dato discutible ${ }^{10}$.

En este sentido, trataremos de mostrar que la movilización italiana no fue tanto la excepción, sino la regla. El objetivo de este trabajo es explicar el fenómeno de las movilizaciones de las comunidades de inmigrantes a Luján a partir de una consideración del cuadro general en el que se inscribían. Este cuadro ha de incluir el contexto general del catolicismo argentino hacia el Centenario, a fin de llamar la atención sobre el hecho de que los italianos no fueron los únicos ni los primeros que se movilizaron a Luján en procesiones cada vez más multitudinarias. Nos interesa focalizar, pues, la década de 1910, años en los cuales las procesiones y manifestaciones católicas se vuelven cada vez más numerosas. No sólo por obra y gracia de los italianos o, por extensión, de los inmigrantes en general, sino porque el clima de movilización y de peregrinación se había vuelto cada vez más intenso. Los Círculos de Obreros fueron también actores clave de estas nuevas formas de movilización. Usualmente, la historiografía suele ubicar la aparición del catolicismo de masas en la década de 1930, cuya expresión más elocuente se habría encontrado en la celebración del Congreso Eucarístico Internacional de 1934. Sin embargo, suele olvidarse que el primer evento de estas características se celebró en Buenos Aires en fecha tan temprana como 1916, cuando se celebró el primer Congreso Eucarístico Nacional. Éste se hizo eco de la naciente oleada de movilización católica de masas que vio la luz hacia el Centenario. De ella fueron partícipes, entre otros, los italianos.

En estas movilizaciones y peregrinaciones que se vuelven cada vez más masivas con el correr de los años, uno de los aspectos que podrá advertirse con nitidez, en especial desde los años del Centenario, es la tendencia a una mayor «nacionalización de las masas» a medida que las peregrinaciones cobraban mayor envergadura ${ }^{11}$. Dicho en otros términos: las peregrinaciones adquieren cada vez más un aspecto nacional; se dirigen a un santuario como el de Luján, que había sido declarado de carácter «nacional» desde fines del siglo XIX, cuando se levantó su basílica de aspecto neogótico ${ }^{12}$; el himno nacional argentino se convirtió en el canto más coreado por todos los asistentes; las banderas nacionales proliferaron igualmente por demás. Las dimensiones de la concurrencia se volvieron cada vez más grandes, así como también pasó a prevalecer en ella una creciente heterogeneidad social y cultural: tan sólo la liturgia

10 Tulio Halperin Donghi, 1975: 765-781.

11 Usamos este concepto en el sentido que en su clásico trabajo le dio George Mosse, 2007.

12 Sobre la construcción del santuario y su significación, véase Jesús Binetti, 2006. 
patriótica, asociada cada vez más a la liturgia religiosa, será capaz de amalgamar públicos cada vez más variados, menos cohesionados por su origen étnico, por su pertenencia a un mismo pueblo de origen, a una misma congregación religiosa o parroquia. A mayor masificación, la liturgia nacional es la que tenderá a prevalecer, como podrá advertirse hacia el final del periodo aquí estudiado. Incluso tenderá a prevalecer el idioma nacional sobre los dialectos y regionalismos, cuanto más grande y variada resulte la concurrencia. Ello no quiere decir que los particularismos regionales, las devociones propias de cada grupo étnico o tradición, los dialectos, desaparezcan por completo o dejen de usarse, desde ya; no obstante, en las procesiones y peregrinaciones más grandes, en las misas más concurridas, cada vez más se diluye el particularismo a fin de garantizar que todos puedan sentirse partícipes. Los particularismos sobreviven a nivel de cada parroquia y congregación. Pero en una peregrinación general de los italianos no es la devoción regional o pueblerina la que se hace ver en primer plano, sino tan sólo aquellos estandartes y banderas que realmente identifican a todos. Con más razón, el himno nacional argentino se vuelve un ingrediente fundamental de esta liturgia que pretende ser por demás incluyente, más allá de los regionalismos y provincianismos. Al santuario nacional de Luján convergía desde fines del siglo XIX infinito número de peregrinaciones de parroquias, congregaciones, pueblos, ciudades y comunidades de inmigrantes; no obstante, hacia el Centenario comenzaron a celebrarse las peregrinaciones así llamadas generales, tanto de los italianos, como de franceses, españoles e irlandeses, que comenzaron a acudir al santuario nacional de la Argentina con banderas nacionales - tanto las de sus países de origen como las argentinas- - Las identidades parroquiales y provincianas quedaban subsumidas en la nacional.

Para retratar este movimiento y dar cuenta de su dimensión nacional, se trabaja sobre todo con uno de los diarios católicos de la Argentina que más pronto adquirió conciencia de la necesidad de darle una dimensión nacional al catolicismo argentino, al propio tiempo que el periódico crecía y alcanzaba una mejor y más amplia distribución a lo largo de todo el territorio. En este sentido, cabe mencionar el diario El Pueblo, que para la década de 1920 comenzó a autodenominarse el «[gran] diario católico argentino» ${ }^{13}$. Dada su dimensión y alcance nacionales, el diario proporciona información muy variada en torno a las diferentes comunidades de inmigrantes, congregaciones, parroquias y diócesis de todo el país. Puesto que no se trata de un diario católico de comunidad (como sí lo eran The Southern Cross, de los irlandeses o Cristoforo

13 Acerca del diario El Pueblo, véase Miranda Lida, 2008. 
Colombo, de los italianos), sino de alcance más general, es una fuente que ofrece la posibilidad de contar con una mirada más amplia que permita comparar el movimiento que se da al mismo tiempo en las diferentes comunidades de inmigrantes, sus semejanzas y diferencias, y el modo en que cada una de ellas vive transformaciones similares en la medida en que la liturgia y la movilización de masas adquiere un aspecto cada vez más nacional.

\section{El CENTENARIO y LAS PEREgRINACIONES GENERALES A LUJÁN}

En un informe titulado Religión e Inmigración que el arzobispado de Buenos Aires encargó en los primeros años del siglo XX se revela minuciosamente una gran cantidad de información sobre la relación entre las diferentes comunidades étnicas y la Iglesia Católica: las distintas formas de asociacionismo y expresiones de la mutualidad étnica, las devociones favoritas, las misas y capillas típicas de cada una de las nacionalidades, las publicaciones periódicas, las escuelas y las congregaciones masculinas y femeninas de origen inmigratorio $^{14}$. Casi nada se dice, no obstante, acerca de las peregrinaciones, que ya para el Centenario habrán de volverse moneda corriente. Sólo se menciona el caso de los irlandeses, que solían preparar una vez cada seis años una peregrinación al santuario de Luján - cada vez que el día de San Patricio caía en domingo- .

El informe de 1907 no se equivocaba. Ni los italianos, ni los españoles, ni los vascos ni los franceses, sólo para mencionar las más importantes comunidades de inmigrantes de raigambre católica, se destacaban por su capacidad de movilizarse en peregrinación. Al menos, no hasta las vísperas del Centenario de la Revolución de Independencia. A fines de 1909, mientras se preparaba la segunda peregrinación general italiana a Luján, el periódico católico $L a$ Voz de la Iglesia publicaba un artículo sobre el tema en el que decía que hasta la fecha la comunidad católica mejor organizada era la irlandesa, no así la italiana, a pesar de su innegable peso numérico. A su vez, el diario católico de los irlandeses, The Southern Cross, recogió el cumplido que le dirigió el diario católico y publicó que «hasta ahora, los italianos no tienen en el país ningún tipo de organización católica ${ }^{15}$. Se refería a la poca presencia que, en tanto que comunidad, los italianos católicos parecían tener en la esfera pública. Pero las cosas estaban a punto de cambiar.

14 «Religión e Inmigración», publicado en La Voz de la Iglesia, del 20.XI al 9.XII.1907.

15 «Italo-Argentine catholics», The Southern Cross, 15.X.1909. (La traducción es de la autora.) La referencia citada a La Voz de la Iglesia está también extraída de aquí. 
Y no sólo para los italianos. En 1908, mientras los italianos preparaban su primera peregrinación general a la basílica de Luján, los españoles comenzaron ellos también a poner en marcha una peregrinación general, que habrá de convertirse en la más típica dentro de esta comunidad: el destino escogido fue el pueblo del Pilar, con el objeto de honrar a la Virgen homónima. La fecha de 1808 no era casual para los españoles: se cumplía un siglo del comienzo de la lucha contra la ocupación napoleónica ${ }^{16}$. La Sociedad Española de la Virgen del Pilar, que reunía a lo más granado de la elite española, fue la encargada de preparar el evento, así como también de redactar y difundir el manifiesto de propaganda.

Cada peregrinación, ya sea a Pilar o Luján, generó un vasto movimiento que no pudo ser detenido fácilmente. Y a comienzos de 1910, por su parte, también los franceses tomaron conciencia de que debían hacerse visibles en la esfera pública con alguna peregrinación general de envergadura. La onda expansiva de las peregrinaciones italiana y española, que desde 1908 se celebraron regularmente entre los meses de octubre y noviembre, movió a la comunidad francesa a querer tener ella también su propia peregrinación. Así tomaron conciencia de que, en pleno año del Centenario, componían la única comunidad de inmigrantes que no había ido a depositar su bandera al santuario nacional de Luján. Acto seguido, abrieron una suscripción a fin de costear una bandera y se dispusieron a organizar la peregrinación que los haría irrumpir en las calles. Dice la proclama preparada por el Círculo de San Luis — la asociación francesa liderada por los bayoneses que se encargó de movilizar a la comunidad gala-:

Se trata en este año del Centenario argentino de recomendar a Dios y a N. S. de Luján los intereses religiosos, morales y materiales de este hospitalario país [...] y llevar a cabo una peregrinación francesa a Luján el día 3 de abril. Todas las naciones representadas en la Argentina tienen colocada su bandera respectiva en el santuario nacional argentino; tan sólo faltan allí los colores franceses ${ }^{17}$.

Pero en rigor, ni siquiera los italianos habían todavía depositado su bandera en la basílica: lo hicieron sólo unos pocos días después que los franceses. Fue una delegación pequeña, enviada por la comisión organizadora de la peregrinación italiana la que se encargó de llevar la bandera, a fin de que estuviera visible para el Centenario ${ }^{18}$. La peregrinación general de los italianos se celebraba durante la primavera, como la mayoría de las peregrinaciones que recibía la

16 «Peregrinación española al Pilar», El Pueblo (en adelante, EP), 23.X.1908.

17 «Círculo de San Luis», EP, 27.II.1910. Véase también «Peregrinación francesa a Luján», $E P$, 3.I. y 1.II.1910; 21 y 22.II.1910. El destacado es nuestro.

18 «Los católicos italianos», EP, 28.IV.1910. 
basílica, motivo por el cual debieron alterar su calendario regular a fin de que la bandera se hiciera allí presente antes del 25 de mayo, en pleno otoño. Los españoles, por su parte, que desde 1908 habían elegido el pueblo de Pilar como destino para sus peregrinaciones, advirtieron que tampoco podían estar ausentes del santuario nacional. Y el 29 de mayo de 1910, tan sólo unos pocos días después de las fiestas del Centenario, organizaron su primera peregrinación a Luján, de la que participó la propia infanta Isabel de Borbón, por entonces de visita en la Argentina ${ }^{19}$. De ahí en más, continuaron organizando dos romerías anuales, una a Pilar y otra a Luján. Si bien preferían como destino devocional el primero, no querían brillar por su ausencia en el santuario nacional, destino favorito de todas las peregrinaciones de la época.

La onda expansiva que el Centenario trajo consigo en materia de peregrinaciones no se agotó en mayo de ese año. A comienzos de 1911 se estableció la Sociedad Católica Popular Italiana, que de ahí en más se encargaría de la organización de las peregrinaciones a la basílica de Luján ${ }^{20}$. Asimismo, también los vascos se plegaron a este movimiento; no querían quedar fuera de una práctica que cada vez convocaba más y más gente:

No podemos ni debemos ser menos que las demás colonias europeas que nos rodean; ellas en diversas ocasiones han sabido presentarse en Luján en número de diez y hasta quince mil provocando la admiración y aplauso general [...] ¿Los vascos constituiríamos acaso una vergonzosa excepción de este certamen de piedad y patriotismo que año tras año se verifica ante los altares de N. S. de Luján? ¡Imposible! No podemos ni queremos ceder el primer puesto a nadie en este terreno [...]; en ello está comprometido nuestro honor de vascongados ${ }^{21}$.

Ir a Luján era parte de un «certamen de piedad y patriotismo» en el que se fueron involucrando las diferentes comunidades de inmigrantes. En la emulación está la clave para entender por qué las peregrinaciones resultaron crecientemente populares: había que ir porque ya habían ido otros, había que tratar de llevar una bandera que no desentonara con respecto a los demás, que fuera grande, llamativa y lo más lujosa posible 22 . Así, ir a Luján se convirtió en cita obligada. Y no sólo para las comunidades de inmigrantes. El mandato también valía para cualquier parroquia, congregación, asociación o escuela católica de Buenos Aires. De hecho, solía ser frecuente que se organizara una infinidad de

19 «Sociedad española del Pilar», EP, 26, 27 y 28.V.1910.

20 Sobre la importancia de esta sociedad llamó la atención Gianfausto Rosoli, 2000: 217.

21 «Gran peregrinación vascongada el domingo 26», EP, 17.XI.1911.

22 En 1911, los españoles llevaron en peregrinación una bandera de raso, que se exhibía acompañada de estandartes bordados en oro. Al respecto, «Peregrinación al Pilar», EP, 16 y 17.X.1911. 
pequeñas peregrinaciones, en especial a partir del mes de septiembre, una vez pasados los rigores del invierno ${ }^{23}$.

El arzobispado de Buenos Aires, por su parte, se lanzó también a organizar una peregrinación arquidiocesana que tenía lugar en el mes de mayo - en fecha cercana a la de los festejos patrios-, para la cual se movilizaba a los párrocos. La más exitosa de ellas fue la que se dio en llamar «del Centenario» (de la Independencia, en 1916), que contó también con la adhesión de la Sociedad Española del Pilar y de la Sociedad Popular Católica Italiana, que se hicieron presentes con sus banderas ${ }^{24}$. Así, pues, ni siquiera la peregrinación arquidiocesana podía pasar por alto la importancia de las asociaciones española e italiana, sin duda las más importantes entre todas las comunidades de inmigrantes.

De hecho, para mediados de la década las peregrinaciones más multitudinarias solían ser las de los italianos que reunían habitualmente más de 15.000 personas, e incluso en algunos casos más de 25.000, según informaría la prensa de la época. La presencia del nuncio apostólico, de nacionalidad italiana, contribuía a resaltar su importancia. Y si bien es probable que tanto la prensa católica como los propios organizadores exageraran las cifras de los asistentes a fin de sobredimensionar su importancia, de cualquier forma no eran desdeñables para la Argentina de 1910 y años subsiguientes.

No obstante, estas cifras no eran excepcionales. No casualmente: la naciente movilización católica de masas cobraba vuelo en los años en que comenzaba a entrar en vigencia la Ley Sáenz Peña. Poco después se anunciaría el estallido de la Primera Guerra Mundial, cuyo impacto se hizo sentir con fuerza en la sociedad argentina ${ }^{25}$. El catolicismo no fue una excepción, ni se mantuvo ajeno a estos hechos. De hecho, no tardaron en celebrarse importantes peregrinaciones y misas pro pace que daban cuenta de hasta qué punto la guerra europea había sacudido a la sociedad argentina ${ }^{26}$.

23 La prensa católica solía publicar la agenda regular de las peregrinaciones que recibía la Basílica. Como ejemplo, véase «Peregrinaciones», EP, 9.IX.1914; «Peregrinaciones a Luján», $E P$, 14.IX.1916. También puede verse la propia publicación del santuario, La Perla del Plata.

24 «Peregrinación del Centenario», EP, 14.V.1916.

25 Al respecto, María Inés Tato, 2008: 725-741; Aníbal Viguera, 1991: 5-33.

26 Ejemplos en este sentido en: «Peregrinación italiana pro pace», EP, 4.X.1914; «Peregrinación española a Luján por la paz europea», EP, 16.X.1914; «Peregrinación española pro paz», EP, 26 y 27.X.1914. También hubo misas por las víctimas de la guerra: «Por los caídos en el frente italiano», EP, 16.I.1916. Después de 1917, comenzó ya a rogarse por el fin de la guerra: al respecto, «Peregrinación arquidiocesana a Luján», EP, 25.IV.1917. Sólo los franceses parecen haber tenido un marcado tono beligerante, en nombre de la patria y de la «defensa nacional». Véase al respecto «La colectividad francesa», EP, 18.IV.1915. 
Pero esos años, sólo los Círculos de Obreros lograron superar a la comunidad italiana en su capacidad de movilización, aunque difícilmente pudieron igualarlos en la basílica de Luján. Si los mejores cálculos arrojan un total de poco más de 25.000 asistentes para las movilizaciones más importantes de los Círculos en la década de 1910 (se destacan por ejemplo las de los años 1913, 1916 y 1917), en la basílica estas cifras solían reducirse incluso a una quinta parte. ¿Por qué? Los Círculos combinaban la peregrinación a Luján — pueblo ubicado a $60 \mathrm{~km}$ de la ciudad de Buenos Aires- con la procesión y la manifestación por las calles céntricas de la capital. Es cierto que la peregrinación de los Círculos a Luján solía ser menos nutrida que la de los italianos, pero cobraba visibilidad de todas maneras porque, una vez que el contingente de viajeros regresaba de la basílica y se apeaba en la estación del ferrocarril, solía ser aguardado por otros que, quizás por no haber podido pagar el boleto de tren para ir a la basílica o simplemente por no haber madrugado lo suficiente - las peregrinaciones solían partir en horas muy tempranas del día-, se aprestaban a sumarse a las filas de manifestantes que desfilarían por el centro de la ciudad, por la Avenida de Mayo en dirección a la catedral. A medida que las columnas avanzaban, nuevos hombres se sumaban a las filas, engrosándolas. El desfile de los Círculos permitía recorrer la prestigiosa Avenida de Mayo y arribar a la Plaza donde se saludaba al arzobispo y se escuchaban las arengas de los oradores de turno ${ }^{27}$.

Era todo un ritual de movilización masculina - las damas no estaban invitadas - que solía culminar con una serie de «vivas» que el público coreaba con entusiasmo, dirigidos o bien a los sacerdotes más populares, o a los líderes del catolicismo social que solían acompañarlos. Los hombres movilizados por los Círculos también participaban regularmente de la visita a los sagrarios que se repetía todos los años en ocasión de la Semana Santa. Mientras las mujeres asistían a los cultos dentro de los templos, los hombres preferían apropiarse de la calle. Esta visita era una movilización pura y exclusivamente masculina que recorría el centro de la ciudad y sus principales iglesias (entre ellas, la Catedral, La Merced, San Ignacio, Santo Domingo, San Miguel). Podía participar en ella cualquier hombre, aún cuando no estuviera enrolado en los Círculos. Es significativo el dato de que se podía asistir sin ser socio; el hecho de que no hubiera restricciones para la participación permitía ampliar casi sin límites el número de los participantes. No se exigía membrecía, pero se apelaba a la hombría de los caballeros para azuzarlos a

27 «La grandiosa demostración del domingo», EP, 13 y 14.X.1913; «El imponente desfile del domingo», EP, 21 y 22.V.1916; «El gran desfile de los Círculos de Obreros», EP, 21 y 22.V.1917. 
movilizarse. O, como se dirá años después, a su «virilidad» ${ }^{28}$. Véase un aviso muy elocuente:

¿Es Ud. hombre de pelo en pecho?

¿Capaz de enrostrar a sus adversarios que le escarnecen y que se burlan por su piedad, por su fe y por su doctrina? Forme en las filas de los Círculos de Obreros en la visita a los sagrarios partiendo de la iglesia de La Merced el Jueves Santo, a las 16 horas. Ud. y sus amigos no deben faltar a esta cita de honor. Que nadie falte ${ }^{29}$.

No fue, pues, necesario aguardar a los años del Congreso Eucarístico Internacional de 1934 para encontrar a los hombres movilizados en las filas católicas. La presencia masculina también se había hecho notar en el Congreso Eucarístico Nacional de 1916. Dice la crónica:

La capital de la república ha confirmado con un varonil y gallardo gesto el concepto de nuestra tradición histórica. El acto preliminar [del Congreso] fue la comunión de hombres en la catedral, y en las numerosas iglesias y capillas de la capital. En la catedral solamente hubo por la mañana 4.000 comuniones de hombres [...] La columna de hombres comenzaba en 25 de Mayo y Rivadavia y se extendía hasta el Paseo de Julio ${ }^{30}$.

Las mujeres, sin embargo, no estaban por completo ausentes. Lo que ocurría era que, como en muchas otras instancias de la vida social de aquellos años, hombres y mujeres no solían compartir los mismos espacios sociales. Peregrinaban y se manifestaban, pero lo hacían la más de las veces por separado. Así, las mujeres no tardaron en preparar su propia visita y procesión de Semana Santa, con un circuito diferente al de los hombres, y sin cruzarse con estos, desde ya. Había peregrinaciones netamente masculinas y a su vez, otras netamente femeninas. A veces, ello respondía al hecho de que el destino de peregrinación se encontraba en un sitio inhóspito, juzgado poco digno de la presencia femenina. Por ejemplo, la peregrinación al santuario de Nuestra Señora de Pompeya, ubicado en un barrio marginal, no contó la presencia masiva de las mujeres entre sus peregrinos sino hasta los años veinte. Y si bien Luján era un sitio al que las mujeres podían acceder con cierta facilidad, dado que estaba equipado con algunas comodidades básicas, sin embargo, los amontonamientos que solían producirse en los vagones del ferrocarril llevarían más de una vez a separar a hombres y mujeres - y más si entre éstas se contaba con un número importante de señoritas jóvenes y solteras-.

En cambio, las peregrinaciones de las comunidades de inmigrantes, así como también las procesiones por parroquia que llegaban desde la ciudad de

28 Lila Caimari, 2005: 165-185.

29 Aviso, EP, 29.III.1923.

30 «El homenaje a la Eucaristía», EP, 24 y 25.VII.1916. 
Buenos Aires o desde los pueblos de la provincia homónima, eran por lo general para toda la familia. Fue en buena medida gracias a ello que los italianos pudieron llegar a reunir hasta 25.000 personas en la basílica de Luján en la década de 1910, convocando las peregrinaciones más numerosas habidas en esa época. ¿Cuáles fueron sus ingredientes básicos?

\section{RADIOGRAFÍA DEL PEREGRINAR}

Con el sólo fervor religioso no basta para lograr que grandes multitudes se movilicen a un destino cualquiera de peregrinación. La peregrinación debía ser preparada por medio de diversas tareas de propaganda y organización. En la década de 1910, no había muchas opciones en materia de propaganda: lo más habitual era la redacción de largas y fervorosas proclamas que solían empezar y terminar con la fórmula «¡A Luján!». Los italianos, que tenían una imprenta propia en su principal casa salesiana de la Capital Federal, podían poner en circulación gran número de volantes a bajo costo. Esos mismos textos se reproducían a su vez en los periódicos y también se exhibían en las puertas de las iglesias y de los colegios católicos de la comunidad. La propaganda incluía además el programa de cada peregrinación: los horarios de los trenes, las misas, el almuerzo previsto, el horario de regreso, el valor del boleto por persona, la cantidad de bandas de música que participarían (ya sea la de los propios salesianos o bien la de la policía u otra fuerza pública) y, por último, los nombres de los que oficiarían de «comisarios» y tendrían a su cargo la tarea de lograr que todo el mundo marchara en orden, cantara lo que tenía que cantar y rezara fervorosamente.

Otra tarea preparatoria importante era la de negociar con las empresas de ferrocarril una serie de tarifas reducidas. Lo común era que las comisiones organizadoras compraran un conjunto de boletos a un precio reducido pactado con antelación, y luego revendieran esos boletos a los peregrinos, conservando una diferencia que se destinaría a mandar imprimir estampas recordatorias del evento o, en el mejor de los casos, a acuñar medallas conmemorativas. Así, era mucho más conveniente comprar el boleto en la parroquia, antes que hacerlo por cuenta propia - las reducciones podían llegar hasta el 50\%-. De hecho, las empresas de ferrocarril hacían descuentos especiales para aquellos que fueran a Luján «en corporación» ${ }^{31}$.

31 Los descuentos especiales se ven reflejados en «Luján y las peregrinaciones», EP, 1.X.1919. 
Era pues conveniente decidir de antemano la participación. No obstante, no siempre ocurría así. El creciente número de gente que se sumaba en el último momento, sin su boleto previamente adquirido, da cuenta de la espontaneidad y el creciente interés que tales eventos despertaban. Las aglomeraciones que se producían con frecuencia en la estación de Once - la gente se apiñaba en los andenes - son buena prueba no sólo de la popularidad de este tipo de eventos, sino además de una cierta cuota de espontaneidad, si bien muy difícil de medir, por cierto ${ }^{32}$. Por ello, una vez que el número de peregrinos comenzó a crecer, las empresas de ferrocarril advirtieron que no les convenía ceder todos los billetes a las comisiones organizadoras; comenzaron a reservarse un lote de billetes para vender por su cuenta, aprovechando la presencia del público que se sumaba en el último momento. Así, hacia la década de 1920, las comisiones organizadoras tuvieron cada vez más dificultades para negociar las tarifas y el número de boletos rebajados con las empresas de ferrocarril, motivo por el cual el número de peregrinos podía verse sensiblemente afectado, como constataremos más adelante.

Y además del transporte, otro detalle imprescindible era contar con la participación de una o más bandas de música. Se procuraba que hubiera más de una por convoy. Una peregrinación con apenas muy escasas bandas musicales corría el riesgo de perder todo atractivo. Las bandas eran capaces de lograr la atracción espontánea del público, a fin de que se sumara a las filas sobre la marcha, engrosando las columnas. Los italianos eran maestros en este aspecto: tenían en los colegios salesianos importantes bandas, que cumplían una función indispensable para ritmar la marcha de cualquier peregrinación o procesión, imponiendo el ritmo de los cantos. Las de los colegios salesianos Pío IX (Almagro) y León XIII (Maldonado) solían ser convocadas para infinidad de actos públicos, y no sólo los organizados por los propios italianos, por cierto. Una peregrinación importante podía tener hasta 10 bandas de música $-\mathrm{y}$ podía, a su vez, utilizar los servicios de más de diez trenes al mismo tiempo-. Cuando no se contaba con banda propia, se recurría a la de la policía local, o bien al Ejército, o al gobierno municipal. Su presencia era decisiva para atraer público que se sumaba al paso de las columnas, desde la estación de tren hasta la basílica.

Otra de las atracciones con la que debía contar toda peregrinación era la gastronomía: era necesario poderle proporcionar a crecientes contingentes de personas la posibilidad de un buen almuerzo al más bajo precio posible. Las

32 Ejemplo de estas aglomeraciones que provocaban reiterados incidentes y demoras a la partida de los trenes en «Peregrinación italiana a Luján», EP, 16.XI.1915; «La peregrinación del Centenario», EP, 29 y 30.V.1916. 
peregrinaciones partían de Buenos Aires muy temprano por la mañana y regresaban a última hora de la tarde, de tal modo que era necesario prever en el programa un buen almuerzo. De tan importante, este tema estuvo desde temprano en la mira de las autoridades eclesiásticas. En 1908, por ejemplo, para evitar que los pocos hoteles cercanos a la basílica de Luján les cobraran precios exorbitantes a los visitantes, se resolvió que:

Bien sabido es que todo visitante que llega a aquel santuario, si no va provisto de su canasta de comida, es tratado duramente por los pocos hoteles o restaurantes que allí hay establecidos, y esto en tiempo ordinario, que cuando se trata de grandes solemnidades, de numerosas peregrinaciones, no hay límite: se cobra sin tasa, a capricho [...] Por ello el señor obispo diocesano ha dado su autorización a dos vecinos y empleados del mismo santuario para instalar en las dependencias anexas al santuario un despacho de pan, frutas y sustancias alimenticias que se venden a precios reducidos, con tarifas a la vista, visados por la administración de la basílica ${ }^{33}$.

Una vez atendidos los problemas del transporte y la alimentación, quedaba por resolver la administración del tiempo libre. Los peregrinos no eran sólo unos devotos más o menos fervientes sino, ante todo, viajeros que querían disfrutar el día que pasaban fuera de la ciudad. A media mañana, una vez llegados a la basílica en sucesivas tandas, según el ritmo de arribo de cada tren, se los recibía con una misa al cabo de la cual llegaría la hora del almuerzo. Por la tarde, y antes de partir, habría una nueva misa, que serviría a su vez para reagrupar a los peregrinos que desde la hora del almuerzo habían tenido tiempo suficiente para dispersarse y pasear por las adyacencias de la basílica, el pueblo o la ribera del Río Luján. Y una vez concluida la última misa de la tarde, y antes de la despedida, tenía lugar la procesión en la plaza y cuadras aledañas, que podía a veces estar coronada, al final, por una kermese o un bazar. En los días de lluvia, también se solía contar con actividades a puerta cerrada, previstas para esos casos: conferencias, actos de declamación, representación de pequeñas piezas de teatro y diversas interpretaciones musicales. A partir de 1923, la visita al Museo Colonial de Luján recién inaugurado se convirtió en cita obligada. Y para los hombres, no era raro que hubiera partidos de fútbol. Incluso se llegó a contar el caso en que se organizó un completo concurso de tiro; esto último permitiría enfatizar la «virilidad» de los hombres católicos movilizados a Luján ${ }^{34}$.

33 «Luján y los peregrinos. Una nueva comodidad», EP, 13.IX.1908.

34 Tanto los exalumnos de Don Bosco como los propios Círculos de Obreros se caracterizaban por ofrecer actividades de recreación exclusivamente masculinas como las mencionadas. Un ejemplo pintoresco lo ofrece el concurso de tiro organizado en 1925. Al respecto, «La gran peregrinación de los exalumnos de Don Bosco», EP, 12 y 13.X.1925. 
Las actividades recreativas variaban, pues, según el público que conformaba la peregrinación: eran diferentes según se tratara de peregrinaciones masculinas, femeninas o mixtas. De hecho se solían organizar peregrinaciones que se preparaban según género. Era ésta una variable importante en las primeras décadas del siglo. Así, mientras que a las mujeres no les quedaba más opción que viajar en tren, a los hombres en cambio se les ofrecía la posibilidad de peregrinar a pie a Luján, cosa que comenzó a hacerse a comienzos del siglo XX - no se consideraba por entonces que ésta fuera una alternativa apta para las mujeres, dado que era una peregrinación que transcurría parcialmente en horas de la noche- - De todas formas, las peregrinaciones y movilizaciones católicas masculinas más importantes continuaron siendo durante largos años las de los Cïrculos de Obreros, que solían ser «sólo hombres» — así se las anunciabaClaro está que había otras que eran sólo «para señoritas» ${ }^{35}$.

Por su parte, las peregrinaciones mixtas presentaban la dificultad de tener que garantizar condiciones especiales para las damas, a fin de que no se sintieran cohibidas por la presencia masculina, y más si ésta llegaba a ser masiva ${ }^{36}$. Fue siempre una preocupación importante por parte de los organizadores la de garantizar la comodidad de los viajeros — en especial, la de las mujeres_-, tanto en los trenes como en los servicios que se ofrecían en Luján ${ }^{37}$. Y más si se tiene en cuenta que las inclemencias del tiempo constituían un factor capaz de disolver cualquier peregrinación, porque entre la estación de tren y la basílica existía un largo trecho que era necesario andar a pie. El trayecto se podía llegar a soportar cuando había buen clima, puesto que las bandas de música acompañaban la marcha y ésta se hacía así llevadera. En caso contrario, era casi imposible porque el camino, por entonces de tierra, se convertía rápidamente en fango y las columnas de peregrinos se disolvían, o casi ni llegaban a conformarse ${ }^{38}$.

35 Por ejemplo, «Peregrinación de señoritas», EP, 30.IX y 1.X.1918; «Peregrinación a Luján de las señoritas estudiantes», EP, 24.VIII.1919.

36 La peregrinación de las Hijas de María del Sagrado Corazón de 1908 — sólo de mujeres- presentó serias complicaciones en materia de transporte. Véase «Peregrinación», EP, 4.X.1908.

37 Y no sólo en Luján, sino también en otros destinos habituales. En ocasión de una peregrinación a Lourdes, se advertía: «Para las señoras se ha conseguido el cómodo local de la Escuela y Patronatos; para los caballeros hay a disposición el abrigo a los peregrinos», «Peregrinación y XX Jornada Eucarística», EP, 31.VIII.1919.

38 En una peregrinación de 1914 ocurrió lo siguiente: «La lluvia [...] impediría organizarse en columna. Los peregrinos en su gran mayoría se vieron precisados a realizar a pie el camino al santuario. Los coches no daban abasto y chapaleando en el fango bajo la lluvia persistente y fría, los fieles hicieron el recorrido en largas hileras», «La peregrinación pro paz», EP, 25.VIII.1914. 
Dada la multiplicidad de factores que era necesario tener en cuenta a la hora de programar una peregrinación, cabe concluir que no era tarea fácil reunir una multitud importante a los pies de la Virgen de Luján. Y menos todavía, de la envergadura de lo que llegaron a ser en su momento las peregrinaciones de los italianos. Las grandes multitudes que lograron movilizar durante la década de 1910 superaban con creces a las convocadas por cualquier otra comunidad étnica: se habló de 17.000 italianos en 1915 y de casi 30.000 en 1920, aunque cabe sospechar que entre estos últimos había gente de otras nacionalidades que se sumaban por la sola atracción del evento ${ }^{39}$. Estas cifras superaron incluso a la de los irlandeses que en 1912, en una de sus peregrinaciones generales más importantes, habían llegado a movilizar 13.000 personas ${ }^{40}$. Sólo los Círculos podían llegar a igualar o incluso superar estas cifras, pero hemos visto que lo hacían más en la ciudad de Buenos Aires que en el santuario.

Debemos preguntarnos pues por las razones de su éxito. Una de sus claves residió en la capacidad de movilizar gente de diferentes lugares de la provincia de Buenos Aires, coordinando la acción conjunta de comisiones organizadoras distribuidas tanto en la ciudad como en diversos pueblos de la provincia - es probable que esta estrategia la imitaran de los irlandeses que en 1911 ya se habían mostrado sumamente preocupados por «uniformar la organización» de sus peregrinaciones a partir de la acción conjunta de diferentes comisiones—41. Y los españoles, a su vez, no tardarían en imitar esta estrategia. Así se hizo frecuente que en ocasión de las peregrinaciones generales Luján recibiera trenes que provenían tanto de Once, como de otras localidades de la provincia de Buenos Aires. Se utilizaban los servicios ferroviarios de distintas compañías: si habitualmente era el Ferrocarril del Oeste el que llevaba a Luján desde la ciudad de Buenos Aires, no se omitió tampoco la contratación de trenes especiales del Ferrocarril Central Argentino o bien del Ferrocarril del Sur para permitir el arribo desde diferentes pueblos y localidades de la provincia ${ }^{42}$. Hasta mediados de la década de 1920, cuando muy lentamente comenzó a usarse el automotor, casi no había más opción que sujetarse a la oferta de trenes y boletos que ofrecían las diferentes empresas de ferrocarril. (No se registran en las crónicas casos de personas que asistieran a caballo desde las zonas rurales de la provincia, aunque no se descarta del todo esta posibilidad, puesto

39 «Peregrinación italiana a Luján», EP, 16.XI.1915; «Más de 30.000 almas en Luján», $E P, 9$ y 10.XII.1920. En este último caso, la crónica aclara que había peregrinos de todas las nacionalidades.

40 «La peregrinación general irlandesa», EP, 18 y 19.III.1912.

41 «Peregrinación irlandesa», EP, 11 y 12.XI.1911. 1911.

42 «Peregrinación italiana a Luján», EP, 10.XI.1915. 
que era el medio de transporte más usado en el medio rural, de donde provenía una porción importante de los visitantes.)

Pero aún cuando se contara con el servicio más o menos puntual de los ferrocarriles británicos, el arte de movilizar multitudes no era fácil. Infinidad de incidentes, algunos de ellos sumamente imprevistos, podían producirse en esos años. Uno de los más frecuentes se deriva de la dificultad de coordinar la llegada de todos los ferrocarriles, y más cuando el número de los convoyes comenzó a crecer. Las demoras en los trenes se hicieron casi inevitables. Si en el Centenario, las peregrinaciones no contaban más que con uno o dos trenes que llegaban sucesivamente y por lo general a horario, a medida que crecía el número de peregrinos se hizo también necesario contar con más vagones y locomotoras, cuya coordinación era cada vez más difícil. Era necesario aguardar a que se retirara un convoy para que llegara el siguiente, provocando atrasos que, a veces, podían llegar a irritar a los peregrinos. En 1915, cuando la peregrinación italiana alcanzaba la inesperada cifra de 17.000 personas - siempre que esta cifra sea exacta y no haya sido objeto de exageración-, se hizo necesario contratar el servicio de nueve trenes que partieron tanto de Once como de La Plata y de otras localidades de la provincia. A su llegada, la coordinación de todos estos convoyes provocó incidentes que no pudieron ser evitados por los organizadores. Para 1919, cuando el número de peregrinos había ya trepado a 26.000 , los percances fueron todavía mayores puesto que, para simplificar el traslado, la empresa de ferrocarril había dispuesto que los viajeros descendieran en la estación Luján, a veinte cuadras de la Basílica, trayecto que se hizo necesario recorrer a pie, a falta de otros medios de transporte. En esa ocasión los italianos habían utilizado los servicios de la exorbitante cifra de catorce trenes, mientras que a los españoles les bastaba de ordinario con cuatro o cinco, y a los franceses, a lo sumo, con dos:

Los trenes llegaron hasta la Estación Luján en perfecto horario; lo único que produjo mala impresión en el público fue el que éstos no llegaran hasta la Estación Basílica. Sería conveniente que el Ferrocarril Oeste tomara en cuenta las molestias que ocasiona el trasladarse desde la Estación Luján hasta la Basílica a pie, más de veinte cuadras, en casos como éste en que es numeroso el número de trenes y por lo tanto de peregrinos, que en pueblos como el de Luján, en que se carece de medios de transporte, se ven obligados a recorrer a pie ${ }^{43}$.

Pero las empresas de ferrocarril eran las que en estos casos tenían la última palabra: ejercían una suerte de tiranía. Decidían cuántos boletos subsidiados pondrían a disposición de las comisiones organizadoras de cada peregrinación,

43 «Peregrinación italiana: 26.000 concurrentes», EP. 10 y 11. XI.1919. 
y en caso de que éstos se agotaran, los interesados no tendrían más opción que comprar el boleto a precio normal, es decir, más caro y sin descuentos. Para 1920, el número de asistentes a la peregrinación italiana trepaba a más de 30.000 , lo cual incrementaba todavía más la posibilidad de que se produjera algún incidente. Y no sólo el hurto de las carteras y monederos de las mujeres, que era por lo demás frecuente.

Lo cierto es que para 1921 las complicaciones con las empresas de ferrocarril alcanzaron tal magnitud que la curia se vio obligada a considerar la idea de suspender, aunque sólo fuera de manera temporaria, las peregrinaciones a Luján. El problema era que las empresas de ferrocarril sobrevendían los boletos, provocando aglomeraciones que luego resultaban difíciles de controlar, a pesar de que las comisiones organizadoras se esforzaban por vender todos los boletos de tren por adelantado:

No obstante las precauciones que se habían tomado, la falta de vigilancia en los andenes de los trenes y en estos mismos hizo que subiera a ellos un número de personas de todo punto superior a la capacidad de los vagones que se habían preparado, por cuyo motivo hubieron de viajar los peregrinos con la incomodidad y los riesgos que son de imaginar [...]. Centenares y centenares de personas que se habían dirigido al Once sin boleto, pudieron obtenerlos de empleados de la empresa que los vendían sin ningún reparo.

Monseñor Duprat [...] piensa que la Iglesia no tiene por qué cargar con responsabilidades que no le pertenecen, de donde deriva la necesidad de suspender las peregrinaciones en tanto no se corrijan las deficiencias observadas anteayer, o no se arbitren otras vías para llegar a Luján ${ }^{44}$.

Finalmente, las peregrinaciones no quedaron suspendidas, pero se hizo lo posible para limitar y controlar el número de pasajes que se vendían. Así, para 1924, el número de trenes que se utilizaron en la peregrinación italiana se redujo a sólo cinco: «habiéndose observado el prudente criterio de limitar los pasajes a una cantidad determinada, el transporte de los pasajeros se realizó en forma cómoda para todos» ${ }^{45}$. En 1928 se utilizaron los servicios de sólo cuatro que partieron de Once, cuyos boletos fueron vendidos por los organizadores a una tarifa reducida; si bien la empresa del ferrocarril Oeste intentó por su parte venderlos sin ningún descuento, no tuvo mayor éxito, dado que la gente no estuvo dispuesta a pagar los 4,25 pesos que cobraron por el boleto de ida solamente - en cambio si uno los compraba por adelantado, podía conseguir el billete de ida y vuelta a 2 pesos, e incluso menos — ${ }^{46}$. Así, la asistencia a la pe-

44 «Peregrinaciones a Luján. Su probable suspensión», EP, 25 y 26.IV.1921. Mons. Duprat era gobernador eclesiástico interino de la arquidiócesis de Buenos Aires.

45 «Efectuóse el domingo la peregrinación italiana a Luján», EP, 10 y 11.XI.1924: 5.

46 «La XX Peregrinación italiana al santuario de Luján», EP, 12 y 13.XI. 1928: 5. 
regrinación italiana no hizo sino reducirse sensiblemente. Por otra parte, por entonces ya comenzaba a ensayarse la utilización del automóvil para las peregrinaciones a Luján, que tendrá su época de esplendor en la década de 1930, cuando la red vial se encuentre algo más consolidada ${ }^{47}$.

La tradicional peregrinación italiana a Luján, sin duda la más multitudinaria de todas las organizadas por las comunidades de inmigrantes desde el momento del Centenario, entró en un declinar progresivo. Pero ello no significa que el catolicismo italiano haya perdido su dinamismo, de una vez y para siempre. En la década del 20, ocupó el primer plano en importantes movilizaciones católicas de masas que tuvieron lugar en pleno corazón de la ciudad de Buenos Aires. No hay que esperar, pues, a la década de 1930 y a la celebración del Congreso Eucarístico Internacional de 1934 para encontrar al catolicismo en movimiento por las calles céntricas de Buenos Aires.

\section{En las calles de Buenos Aires}

No es necesario abundar acerca de la fuerte presencia que el catolicismo italiano tenía en la ciudad. Ya el informe mencionado de 1907 se encargaría minuciosamente de consignar su presencia. Importantes congregaciones de origen italiano se hicieron cargo de la atención de parroquias de la ciudad. Fernando Devoto ha estudiado el caso de los salesianos en la Boca; la orden de Don Bosco ocupó además la populosa parroquia de San Carlos y la capilla Mater Misericordiae (conocida popularmente como la «de los italianos»). Esta última tenía un papel destacado en el catolicismo italiano, puesto que era el centro en el que se estableció la Sociedad Católica Popular Italiana, encargada de organizar los eventos de masas. Y además de las importantes capillas y parroquias salesianas, se contaban las de otras congregaciones italianas como los Oblatos de María o los capuchinos que, si bien de llegada más tardía al país y de menor presencia numérica, se destacaban por atender santuarios populares como el de San Roque o el de Nuestra Señora del Rosario en el barrio de Pompeya.

Además de atender el culto en las diferentes iglesias con sus misas y sus devociones, los italianos solían salir a la calle cada vez que se prestaba la ocasión. Importantes templos de la ciudadad ministrados por congregaciones ita-

47 «Peregrinación en automóvil y en ómnibus a Luján», EP, 4.IX.1927: 5; «Visita piadosa al santuario de Luján», EP, 4.III.1931: 5. La red vial que el gobierno de Justo tanto contribuyó a expandir fue decisiva, por ejemplo, para la peregrinación a Luján que se hizo en el marco del Congreso Eucarístico Internacional de 1934. 
lianas - San Carlos, Nueva Pompeya - eran centros muy visitados por peregrinaciones que arribaban desde los diferentes rincones de la ciudad. Asimismo, cada parroquia o capilla celebraba puntualmente su fiesta patronal, que tenía cita obligada en la calle, con procesiones típicas que solían recorrer las calles aledañas al templo y la plaza del barrio, cuando la hubiere. Otra expresión pública muy visible de la iglesia italiana en los barrios fue, en especial a partir de la década de 1920, las misiones populares celebradas bajo carpas en barrios marginales de la ciudad. Los oblatos de la Virgen María, junto con los redentoristas (congregación de origen alemana afincada en la parroquia de Nuestra Señora de Guadalupe en Palermo), tuvieron un papel destacado en este tipo de actividad al aire libre, y su presencia no fue pasada por alto por el catolicismo de la ciudad en su conjunto, dado que la información solía salir destacada en las páginas de la prensa católica ${ }^{48}$.

Pero no debe interpretarse que los italianos constituyeran una excepción en este vasto movimiento que los barrios y las parroquias verificaron, en especial, en el periodo de entreguerras. En realidad, se trata de un fenómeno que se hace eco del amplio crecimiento que el asociacionismo barrial estaba atravesando en diferentes lugares de la ciudad ${ }^{49}$. Estas asociaciones barriales, desde las sociedades de fomento hasta las asociaciones parroquiales, eran muy activas ya sea en la construcción de la sociedad barrial, así como también de la propia parroquia y todas sus actividades (colectas, fiestas religiosas y sociales, recreación, educación popular, caridad y acción social, catecismo y recreación infantil, etc.). Citamos un ejemplo al respecto que puede servir de muestra sobre el movimiento católico, al mismo tiempo que italiano, en los barrios:

Los italianos de Giovinazzo y pueblos vecinos, devotos de la Santísima Virgen bajo la advocación de Corsignano, conmemoraron con gran solemnidad de carácter religioso y popular el día de su excelsa patrona. Se realizó una procesión con el siguiente recorrido: Martín Rodríguez, Suárez, Almirante Brown y Olavarría. El orden de la procesión fue el siguiente: banda de música, cruz, niños, colegio de María Auxiliadora, estandarte de la parroquia, señoras, banda de música de los Huerfanitos de Don Bosco, efigie de la virgen, clero y ministros sagrados, hombres en corporación ${ }^{50}$.

48 Entre otros ejemplos, «La misión bajo carpas en Villa Devoto», EP, 12.V.1927: 5; «La séptima misión bajo carpas celebrada en Villa Pueyrredón», EP, 9.XI.1927: 5; «La gran misión catequística en Villa Mitre», EP, 1.V.1928: 1. Sobre las misiones bajo carpas, véase Mario Gill, 2006.

49 El estudio clásico es Leandro Gutiérrez y L. A. Romero, 1995. Sobre la sociabilidad barrial y parroquial, Miranda Lida, 2005.

50 «Una fiesta italiana», EP, 29.VIII.1913. 
Este tipo de celebración barrial, en general pequeña, dado que su alcance no iba más allá de unas pocas cuadras en el radio parroquial, podía estar acompañada por misa en italiano. Sin embargo, a medida que creció el número de los asistentes, o al menos su heterogeneidad, el recurso al idioma español se hizo tanto más frecuente puesto que era habitual que los propios italianos solicitaran la utilización del español; la lengua local era de más fácil comprensión ante la multiplicidad de dialectos de la península que podía hacerse presente en una misma celebración ${ }^{51}$. (De todas formas, el italiano continuó utilizándose en la celebración religiosa. En las peregrinaciones a Luján, por ejemplo, había misas u homilías que invariablemente se daban en ese idioma.) La utilización del español en la predicación, en lugar de una casi infinita diversidad de dialectos, habría servido desde temprano como un factor más de integración y nacionalización del inmigrante, junto con la educación pública y el servicio militar obligatorio, entre otros ${ }^{52}$.

A ello se le sumarían otros, a medida que la movilización católica crecía en proporciones. Un dato a destacar en este sentido es la centralidad que adquirió el himno nacional argentino en la movilización católica posterior al Centenario. El himno era uno de los cantos más conocidos por todos los asistentes y por lo tanto uno de los más fáciles de corear al unísono, acompañado a su vez por las infaltables bandas de música. Tanto el sistema escolar como la conscripción militar obligatoria establecida por ley en 1901 habían hecho posible que el himno fuera conocido por casi todos los asistentes. Corear el himno en las grandes movilizaciones se convirtió en un ritual frecuentemente reiterado desde el Centenario hasta los tempranos años de la década de 1930. Esta costumbre contribuiría a darle su tono al catolicismo de estas décadas. Se lo cantaba en las procesiones, en la celebración del Corpus - tanto en los barrios como en el centro de la ciudad, frente a la Catedral-y, sobre todo, se lo coreó a viva voz en ocasión del Congreso Eucarístico Nacional de 1916, durante el desfile que circuló desde la Plaza de Mayo hasta la del Congreso ${ }^{53}$. Cuanto más grande fuera una manifestación católica, y por ende más heterogénea, más se prestaba a hacer del himno nacional el canto favorito de la multitud. Incluso

51 «Religión e inmigración (sigue)», La Voz de la Iglesia, 28.XI.1907.

52 Sobre la relación entre el idioma y la idea nacional, Eric Hobsbawm, 1992; Lilia Ana Bertoni, 2001.

53 Sobre el Congreso de 1916, véase «El homenaje argentino a la Eucaristía. El magno acto de ayer», EP, 24 y 25.VII.1916. Otros ejemplos: en la colocación de la piedra fundamental de un oratorio festivo salesiano, «Colegio y oratorio festivo», EP, 14.VII.1914; en la manifestación de los Círculos de Obreros, «La grandiosa demostración del domingo», EP, 13 y 14.X.1913; en una procesión de la parroquia de la Merced, «La gran procesión del domingo», $E P, 5$ y 6. VIII.1918, entre otros ejemplos. 
en las más importantes peregrinaciones generales a Luján, ya sea de italianos o de españoles, se verifica su presencia, aunque en estos casos solía también estar acompañado por la ejecución de los himnos reales correspondientes a cada una de estas nacionalidades ${ }^{54}$.

Otro de los ingredientes que se tornó infaltable a partir del Centenario fue la realización de desfiles gimnásticos donde los jóvenes hacían exhibiciones de destrezas físicas. En este aspecto, los italianos jugaron un papel sumamente destacado, puesto que los gimnastas provenían en casi todos los casos de los colegios salesianos ${ }^{55}$. Los sacerdotes de Don Bosco habían desarrollado en sus parroquias y colegios los cuerpos de exploradores - suerte de boy scouts católicos- que, en ocasiones importantes, salían marcialmente a la esfera pública haciendo relucir sus pulcros uniformes y enarbolando sus estandartes, acompañados a su vez por bandas de música que no omitían la ejecución del himno nacional. Cantado al paso de estos cuerpos uniformados, servía como un poderoso imán para atraer al paseante ocasional a fin de que se una a las filas, o al menos se acerque o lo siga de lejos. Hacia 1917, comenzó a organizarse regularmente un desfile anual de alumnos y exalumnos de las escuelas salesianas que, encabezados por los exploradores, se dirigían desde la Plaza de Mayo hasta la Plaza San Martín, a través de la calle Florida, en un desfile acompañado de música y vítores que imitaba a los que realizaban distintos cuerpos militares en ocasión de las fiestas patrias ${ }^{56}$. Se esperaba que, a medida que el desfile circulaba por plena calle Florida - una de las arterias más prestigiosas de la Buenos Aires de los años del Centenario- se podría captar fácilmente la atención del público, tanto la de la gente que circulaba por la calle como la de los vecinos que desde los balcones podrían presenciar el espectáculo e incluso arrojar flores a su paso, como era habitual que ocurriera en este tipo de eventos públicos.

Y a medida que los años transcurrieron el desfile salesiano fue adquiriendo cada vez mayor envergadura, a la par que se convertía en una fiesta cada vez menos típicamente salesiana —o italiana—, para volverse lisa y llanamente

54 Por ejemplo, véase «La gran peregrinación italiana a Luján», EP, 10 y 11.XI.1924; «Realizóse la peregrinación española», EP, 14 y 15.XII.1925.

55 El papel de la gimnasia y las exhibiciones de destreza física fue un recurso para la movilización de masas ampliamente utilizado en los escenarios más diversos. Al respecto, George Mosse, 2007; Bertoni, 2001.

56 En 1917 se anunciaba: «Esta tarde a las 5 tendrá lugar el desfile de los exploradores de Don Bosco y gimnastas desde la Plaza de Mayo hasta la del General José de San Martín, por la calle Florida. Ante la pirámide de Mayo se cantará el himno nacional y se pronunciarán discursos y cantos a la bandera, organizándose la marcha a la Plaza San Martín, donde pronunciarán discursos exploradores y gimnastas», «Gran desfile de Don Bosco», EP, 5.I.1917. 
una festividad de carácter nacional. Veamos un ejemplo. Para 1929, el desfile de Don Bosco adquirió dimensiones inéditas en Buenos Aires, no sólo por la presencia de un creciente número de exploradores y alumnos salesianos, sino porque estos desfilaron a lo largo de un trayecto que alcanzó las 35 cuadras, acompañados de creciente público. La procesión iba presidida por una carroza en la que se exhibía una monumental imagen del beato italiano, fundador de la orden, rodeada de banderas y gallardetes, además de las flores que eran lanzadas desde los balcones. Las bandas de música y los gimnastas completaron el desfile, que circuló desde la Plaza de Mayo, en dirección hacia el Congreso nacional para concluir ante el templo salesiano de San Carlos en el barrio de Almagro. Allí se instaló un palco desde el cual el presidente argentino Hipólito Yrigoyen recibió a la cabeza de la procesión, en medio de los vítores de la multitud. Fue una marcha sin precedentes para el catolicismo de masas de Buenos Aires, debido a su vasto despliegue a lo largo del espacio urbano, extendiéndose desde el centro hacia los barrios.

Aquel desfile tuvo entre el público mucho más que exalumnos de los colegios salesianos; hubo quienes se sumaron por curiosidad engrosando las columnas a su paso; otros, en cambio, se limitaron a observar el desfile desde las terrazas, aceras o balcones. Un dato novedoso fue la utilización de una serie de altoparlantes, tanto en la Plaza de Mayo como en la del Congreso y a la llegada a la basílica de San Carlos. Otro no menos curioso fue la transmisión radial de la palabra de Monseñor Napal, principal orador de esa fecha, un conocido agitador entre las multitudes católicas. Y no menos digno de mención fue la presencia de infinidad de banderas, no sólo argentinas y pontificias, sino además de infinidad de lugares, tanto de las provincias que estaban «representadas» en el evento, como del extranjero. Véase una descripción:

El éxito extraordinario de la manifestación religiosa se podía prever desde las primeras horas de la tarde cuando comenzaron a llegar a la plaza del Congreso las primeras columnas de exploradores y gimnastas. Luz, colores, alegría, música, canto, marcialidad y afectos [...]. Rompieron la marcha a las 15,45 los millares de exploradores de Don Bosco, entre ellos destacábase la columna de los gallardos correntinos: seguíanles los demás y los gimnastas. Bandas y fanfarrias, banderas y estandartes entonaban y embellecían el ambiente.

Armada sobre un chasis «lancia» de la conocida fábrica italiana, la carroza presentaba un atrayente aspecto [...] iba cubierta por rico paño y adornada con flores y con los escudos argentinos y de la institución salesiana. [...]

Grupos de exploradores de Don Bosco tremolaban las banderas de 43 países, representando los que tienen alguna obra salesiana. Otro detalle interesante lo dieron más de 70 carteles con los nombres de las ciudades y pueblos en los cuales hay casas salesianas y los escudos de las provincias argentinas que llevaba un grupo de niñas. Pajes bien trajeados; niñas hermosamente ataviadas; banderas y colores formaban un conjunto hermosísimo. [...] 


\begin{abstract}
Muchas personas creen que morirán sin volver a ver tan imponente y suave despliegue de fuerzas ${ }^{57}$.
\end{abstract}

No sólo se hacía evidente el tono cosmopolita representado por tal multiplicidad de banderas extranjeras, que componían una verdadera Babel; también se destacaba el hecho de que las provincias no dejaron de estar representadas, de tal modo que el desfile adquiría así un aspecto tanto cosmopolita como nacional al mismo tiempo. Ante tal despliegue de banderas y escudos, habría sido difícil identificar a simple vista de qué tipo de festividad se trataba; no era fácil darse cuenta que el único objeto de esa enorme movilización era aclamar a Don Bosco, puesto que la carroza que llevaba su imagen quedó prácticamente opacada ante las banderas, los clamoreos de la multitud, la música, la exhibición gimnástica y la figura de Hipólito Yrigoyen. La fiesta salesiana se había convertido en una verdadera fiesta popular, a la par que nacional y de tono cosmopolita. Como ocurrió con la peregrinación italiana a Luján a partir de 1920, a la que se le sumaría gente de otras nacionalidades, la fiesta italiana era, en realidad, cada vez menos italiana.

La movilización italiana se convertía, lisa y llanamente, en un fenómeno de masas donde se podía ostentar la bandera nacional junto con otras tantas banderas más. Nacionalizarse era un modo de masificarse, y más cuando, luego de 1929, comenzó a declinar súbitamente el arribo de extranjeros a la Argentina. Si a comienzos de siglo se le pedía al sacerdote de las iglesias italianas que predicara en español para que lo comprendiera una asistencia que hablaba los más surtidos dialectos, también las manifestaciones católicas en las calles de Buenos Aires debieron nacionalizarse a fin de captar la atención de un mayor número de público. Poco importaba ya que los italianos hubieran sido sus organizadores. Para los primeros años treinta, la movilización católica habrá de tornarse plenamente nacional. Una vez masificadas, las fiestas italianas terminaron abriéndole el paso al tono nacionalista que adoptó el catolicismo de masas de los años treinta. Y como en cualquier otra movilización católi$\mathrm{ca}$, los italianos cantaron religiosamente el himno nacional argentino.

\title{
5. Desenlace
}

El final de esta historia es bastante conocido: para los años treinta, las banderas italianas quedaron opacadas por las nacionales, y el catolicismo de masas, desarrollado con gran vigor, adquirió un tono nacionalista que era capaz

57 «Fue un acontecimiento que sorprendió a la capital de la República!», EP, 7 y 8.X.1929: 1. 
de arrasar con el cosmopolitismo de principios de siglo ${ }^{58}$. Las banderas argentinas se imponían a las extranjeras, mientras la concurrencia que se hacía presente en las movilizaciones católicas crecía hasta niveles inéditos.

En 1930, cuando todavía gobernaba el país un ya muy cuestionado y anciano Hipólito Yrigoyen, se hizo evidente que el criollismo y las banderas nacionales, cuando se sumaban a las procesiones religiosas, les daban a éstas un atractivo sin par. En junio de ese año tuvo lugar en Buenos Aires la celebración del Tercer Centenario del milagro de la Virgen de Luján, que fue celebrado con una procesión todavía más pintoresca que la que habían movilizado los salesianos el año anterior. Se recorrieron 80 cuadras, desde la parroquia de San Nicolás de Bari en el barrio Norte, hasta la Plaza de Mayo para culminar el paseo en la Plaza Flores, en una procesión que tenía un fuerte aspecto nacionalista y telúrico:

Sobre una vieja carreta evocadora de tiempos pretéritos tirada por tres yuntas de bueyes en un trono rústico, la Virgen de Luján hizo un paseo triunfal y recibió su apoteosis. El pueblo todo se volcó a su paso [...]. Apenas pudo abrirse camino por entre la apretada y devota muchedumbre, la pintoresca carreta que conducía la imagen. Se le agregó un interesante cortejo de gauchos jinetes como representación genuina de los que debieron acompañarla en su primitiva carreta de Luján. La gallardía de esta guardia de honor criolla, vestida a la antigua usanza, con el clásico poncho y bombachos, causó muy buena impresión [...]. Las flores no cesaban de caer sobre la imagen y su vehículo, y numerosas casas iluminaban sus frentes y balcones, las aclamaciones populares, el trueno de las bombas, el tintineo clamoroso de las campanas, exaltaron todavía más la $\mathrm{fe}^{59}$.

En este marco, no es casual que las banderas italianas comenzaran a perder relevancia en el seno del catolicismo porteño. Cuanto más masivo se hiciera el catolicismo, menos lugar habría para los italianos católicos. Si bien es cierto que estos se hicieron presentes con sus banderas en el Congreso Eucarístico Internacional de 1934, casi pasaron inadvertidos: en el mar de gente que se reunió en Buenos Aires en esa ocasión, los italianos no podían sino ocupar una porción que parecía minúscula. En medio de la multitud casi infinita que asistió a esos actos, las banderas italianas no lograron descollar. Cuanto más masivo se volvía el catolicismo de masas, menos espacio dejaba para la diversidad nacional y la exhibición de las más variadas banderas. Las peregrinaciones italianas a Luján, que en su mejor momento habían logrado reunir unas 25.000 personas, se tornaron cada vez menos significativas, ante una movilización católica como la de 1934, que llegó a reunir a más de un millón de personas.

58 En efecto, el informe que mandó elaborar el arzobispado en 1907 hablaba de una «concurrencia cosmopolita» en las iglesias porteñas. «Religión e inmigración», La Voz de la Iglesia, 20.XI.1907.

59 «El paso de la imagen de N. S. de Luján», EP, 2 y 3.VI.1930: 7. 
En una sociedad más pequeña como la de principios de siglo, donde los espacios de movilización en la esfera pública se encontraban reducidos a circuitos relativamente acotados que iban desde la Plaza de Mayo a la Plaza de San Martín o del Congreso, las peregrinaciones de los italianos tenían un peso específico mayor a lo que ocurrirá en los treinta, cuando los espacios para la movilización católica de masas se extendieron a dimensiones casi infinitas, llegando a adquirir visos monumentales. En la década de 1910, organizar una peregrinación a Luján podía ser casi una verdadera proeza; en cambio, esa misma peregrinación, veinticinco años después habría pasado casi inadvertida. Las dimensiones de la sociedad (y del catolicismo de masas) habían crecido tanto que ya no se podía apelar a los mismos recursos que antaño para atraer multitudes. Por el sólo efecto de la masividad, el catolicismo italiano perdía peso relativo en el catolicismo argentino; no puede interpretarse que haya habido intención de desplazarlo adrede. En los años treinta, fueron otras las dimensiones de las multitudes, en comparación con las de los tiempos del Centenario. Fue así que la bandera italiana, que había movilizado las más importantes peregrinaciones a Luján desde 1908, debió dejarle el primer plano a la bandera nacional que, unida a la pontificia, le daría el tono al catolicismo de masas de los treinta.

\section{BIBLIOGRAFÍA}

Auza, Néstor T., «La experiencia pastoral con las colectividades extranjeras en Buenos Aires, 1900-1961», Iglesia e Inmigración en la Argentina IV, Buenos Aires, CEMLA, 2001: 279-295.

Auza, Néstor, «Una aproximación a la relación entre clero, población e inmigración en la provincia de Santa Fe», Iglesia e Inmigración, 2 (1994): 43-59.

Auza, Néstor, «La Iglesia argentina y la evangelización de la inmigración», Estudios Migratorios Latinoamericanos, 14 (1990): 105-137.

Bertoni, Lilia Ana, Patriotas, cosmopolitas y nacionalistas. La construcción de la nacionalidad argentina a fines del siglo XIX, Buenos Aires, FCE, 2001.

Binetti, Jesús, El augusto recinto. Conflictos y debates en torno a la construcción de la Basílica de Luján, 1885-1890, Universidad Nacional de Luján, tesis, 2006.

Caimari, Lila, «Sobre el criollismo católico. Notas para leer a Leonardo Castellani», Prismas. Revista de historia intelectual, 9 (2005): 165-185.

Castro, Martín, «La Iglesia Católica y la religiosidad popular de los italianos del Mezzogiorno en el puerto de Mar del Plata, entre las décadas de 1920 y 1940», Estudios Migratorios Latinoamericanos, 34 (1996): 569-591.

Ceva, Mariela, «La acción pastoral y los inmigrantes», Todo es Historia, diciembre de 2000. 
Ceva, Mariela, «La Italica Gens y la inmigración italiana en la Argentina, 19101925», Estudios Migratorios Latinoamericanos, 49, 2005: 585-602.

Orden, M. Liliana da, «Una fiesta popular y la consolidación de una dirigencia étnica: las romerías españolas de Mar del Plata, 1897-1930», Estudios Migratorios Latinoamericanos, 19 (1991): 379-402.

Devoto, Fernando, «Catolicismo y clericalismo en un barrio italiano de Buenos Aires (La Boca) en la segunda mitad del siglo XIX», Estudios sobre emigración italiana a la Argentina en la segunda mitad del siglo XIX, Nápoles, 1991: 199-229.

Gallo, Ezequiel, La Pampa gringa: la colonización agrícola en Santa Fe, 1870-1895, Buenos Aires, Edhasa, 2004.

Gill, Mario, «Un estudio de sociabilidad barrial: la parroquia de San Roque (19211944)», tesis, UCA, 2006.

Gutiérrez, Leandro y Romero, L. A., Sectores populares, cultura y política. Buenos Aires en la entreguerra, Buenos Aires, 1995.

Halperin Donghi, Tulio, «Algunas observaciones sobre Germani, el surgimiento del peronismo y los migrantes internos», Desarrollo Económico, 46/56, 1975: 765- 781.

Hobsbawm, Eric, Naciones y nacionalismo desde 1780, Barcelona, Crítica, 1992.

Lida, Miranda, «Iglesia y sociedad porteñas. El proceso de parroquialización de la arquidiócesis de Buenos Aires, 1900-1928», Entrepasados, año 14, 28, 2005: 125-141.

Lida, Miranda, «Una modernización en clave de cruzada: el diario católico El Pueblo en la década de 1920», Revista Escuela de Historia, Facultad de Humanidades, Universidad Nacional de Salta, 7 (2008): 45-64.

Martos, Susana Beatriz, «San Roque. Espacio devocional y sociedad», Néstor Auza (comp.), Iglesia e Inmigración en la Argentina V, Buenos Aires, CEMLA, 2005: 53-76.

Míguez, Eduardo, «Política, participación y poder. Los inmigrantes en las tierras nuevas de la provincia de Buenos Aires en la segunda mitad del siglo XIX», Estudios Migratorios Latinoamericanos, 6-7 (1987): 337-378.

Mosse, George, La nacionalización de las masas. Simbolismo político y movimientos de masas en Alemania desde las guerras napoleónicas al Tercer Reich, Buenos Aires, Siglo XXI, 2007.

Rosoli, Gianfausto, «Las organizaciones católicas y la inmigración italiana en la Argentina», Fernando Devoto y Gianfausto Rosoli, La inmigración italiana en la Argentina, Buenos Aires, Biblos, 2000: 211-239.

Santamaría, Daniel J., «Estado, Iglesia e inmigración en la Argentina moderna», Estudios Migratorios Latinoamericanos, 14 (1990): 139-180.

Siegrist de Gentile, Nora, «Sacerdotes extranjeros y argentinos en el censo de la ciudad de Buenos Aires de 1855», Iglesia e Inmigración en la Argentina, Buenos Aires, CEMLA, 1991: 153-176. 
Stoffel, Edgardo, «El clero secular español y su actuación en Santa Fe, 1856-1930», Iglesia e Inmigración en la Argentina 3, Buenos Aires, CEMLA, 1997: 71-99.

Stoffel, Edgar, «El clero secular nacional. Ámbitos de reclutamiento y nacionalización. Estudio de las vocaciones sacerdotales ingresadas en Santa Fe hasta 1930», Iglesia e Inmigración en la Argentina 2, Buenos Aires, CEMLA, 1994: 61-85;

Tato, María Inés, «La movilización de la sociedad argentina frente a la Primera Guerra Mundial», Silvia C. Mallo y Beatriz I. Moreyra (coords.), Miradas sobre la historia social en la Argentina en los comienzos del siglo XXI, Córdoba-La Plata, Centro de Estudios Históricos «Prof. Carlos S. A. Segreti»-Centro de Estudios de Historia Americana Colonial (CEHAC), 2008: 725-741.

Ussher, Santiago, Las Hermanas de la Misericordia irlandesas. Apuntes históricos sobre sus cien años en la Argentina. 1856-febrero 24-1956, Buenos Aires, 1955.

Viguera, Aníbal, «Participación electoral y prácticas políticas de lo sectores populares en Buenos Aires, 1912-1922», Entrepasados, 1 (1991): 5-33.

Zanatta, Loris, Del Estado liberal a la nación católica. Iglesia y Ejército en los orígenes del peronismo, Buenos Aires, 1996.

\section{TO LUJÁN! \\ THE IMMIGRANT COMMUNITIES AND THE EARLY CATHOLICISM OF THE MASSES, 1910-1934}

The objective of this work is to explain the phenomenon of the mobilizations of immigrant communities in Luján, based on a consideration of the bigger picture in which they took place, including the general context of Argentine Catholicism near the time of the Centennial. As such, it must be noted that Italians were not the only group, nor the first one, that organized processions in Luján that attracted increasingly greater numbers of participants. Our focus is on the decade of 1910, years in which Catholic processions and demonstrations were becoming every more numerous. Usually historigraphic studies tend to date the appearance of Catholicism of the masses from the decade of the 1930s, the most telling expression of which can be found in the celebration of the 1934 International Eucharistic Congress. Nevertheless, it is often forgotten that the first event of these characteristics was celebrated in Buenos Aires as early as 1916, with the first National Eucharistic Congress. This echoed the nascent wave of Catholic mass mobilizations that began at the time of the Centennial. Among others, the Italians were active in this wave.

KEY WORDS: Immigration, Catholicism, politics of the masses, social movements, Buenos Aires. 